\title{
A Bromophosphonate Analogue of Lysophosphatidic Acid Surpasses Dacarbazine in Reducing Cell Proliferation and Viability of MeWo Melanoma Cells
}

\author{
Duy Nguyen', Oanh Nguyen¹, Honglu Zhang2, \\ Glenn D. Prestwich ${ }^{2}$ and Mandi M. Murph ${ }^{1}$ \\ ${ }^{1}$ Department of Pharmaceutical and Biomedical Sciences, \\ The University of Georgia, College of Pharmacy, Georgia, \\ ${ }^{2}$ Department of Medicinal Chemistry, The University of Utah, Salt Lake City, \\ United States of America
}

\section{Introduction}

The incidence of melanoma continues to rise, in particular among adult males residing in the U.S. (Jemal, Siegel et al. 2010). Although this disease is treatable in its early stages, diagnosis of or progression to an advanced, metastatic disease stage drastically reduces the prognosis, with few patients surviving 5 years. It is especially disturbing that there is a lack of FDA-approved therapeutics that can adequately treat the disease and very low percentages $(5-15 \%)$ of patients who will respond to these traditional chemotherapeutics (Thompson, Morton et al. 2004). Even among responders, the response to therapy is usually unsustainable over the long-term, with approximately $10.8 \%$ of patients achieving long-term survival (Kim, Lee et al. 2010). Dacarbazine or DTIC is considered the most appropriate cytotoxic chemotherapy, but response rates are poor. Many other single-agents have been tried with response rates $\leq 18 \%$, these include temozolomide, lomustine, carmustine, cisplatin, carboplatin, vincristine, vinblastine, vindesine, paclitaxel, docetaxel, gemcitabine and topotecan. (Thompson, Morton et al. 2004)

Without patient selection to decipher who belongs to the small portion of responders, the more common approach to therapy is to enroll patients into a clinical trial. Recent trials examining more targeted and selective agents like PLX4032 (Flaherty, Puzanov et al. 2010) and ipilimumab (Hodi, O'Day et al. 2010) have further reinforced this clinical ideology due to the successes observed among some patients. Although the development of chemoresistance is an impediment to achieving cure using these novel agents, they represent the current ideal and a hopeful future for promising targeted therapeutics. Thus, more specific drugs are desirable to increase the options for therapy and improve overall outcomes.

A recently discovered and highly "druggable" method to target melanoma cells is through inhibition of a G protein-coupled receptor (GPCR) that is responsible for viability among melanomas that predominantly express it (Altman, Gopal et al. 2010). This GPCR is called the Lysophosphatidic Acid (LPA) receptor 3 or the LPA3 receptor (Bandoh, Aoki et al. 1999) and is found along the cell surface of specific types of melanomas. In addition, the high- 
affinity ligand that binds to this GPCR is lysophosphatidic acid (Aoki, Bandoh et al. 2000). Interestingly, the lysophospholipase $\mathrm{D}$ that is responsible for the vast majority of the production of LPA from lysophosphatidylcholine is also expressed extracellularly and is a major target in melanoma (Altman et al. 2010; Liu, Murph et al. 2009). This enzyme, autotaxin (ATX), was first isolated from the conditioned medium of melanoma cells and was thought to be responsible for melanoma cell motility (Stracke, Krutzsch et al. 1992). Recent studies have shown that targeting either the LPA3 receptor or ATX effectively reduces melanoma cell viability (Altman et al. 2010). Furthermore, research devoted to producing inhibitors and antagonists targeting the ATX-LPA receptor axis has yielded a large variety of compounds (Albers, Dong et al. 2010; Altman et al. 2010; Baker, Fujiwara et al. 2006; Block, Duff et al. 2010; Hoeglund, Bostic et al. 2010; Hoeglund, Howard et al. 2010; North, Howard et al. 2010; Xu, Yang et al. 2009), suggesting the critical role of this pathway in cancer.

Herein we tested the in vitro capability of another antagonist of the LPA3 receptor and the lysophospholipase D activity of autotaxin, BrP-LPA, among the MeWo melanoma cell line. This compound inhibits the growth of in vivo lung carcinoma and angiogenesis $(\mathrm{Xu}$ and Prestwich 2010), but was untested in melanoma, a disease in dire need of additional therapeutics. We compared the BrP-LPA anti diastereoisomer to the BrP-LPA diastereomeric mixture and observed a slight enhancement of activity against MeWo cells using the mixture. Surprisingly, this effect was reduced or absent in the presence of a 24hour pretreatment with dacarbazine, a traditional alkylating chemotherapeutic agent, suggesting that single-agent therapy is superior. We have observed an in vivo effect on reducing the number of metastatic melanoma lesions in the lungs of mice treated with $\mathrm{BrP}$ LPA, in comparison to control (data not shown). It is unclear whether our in vitro results would extend to in vivo treatment, but if so, then the implications of this study would require naïve patients for clinical trials, an extremely difficult group to have available.

\section{Materials and methods}

MeWo fibroblast malignant melanoma cells were acquired from ATCC (Manassas, VA) and maintained in Cellgro RPMI (Mediatech, Inc., Manassas, VA) supplemented with 5\% fetal bovine serum (Sigma-Aldrich, St Louis, MO). BrP-LPA compounds, the anti diastereoisomer and diastereomeric mixture, were synthesized as previously described (Zhang, $\mathrm{Xu}$ et al. 2009) and reconstituted in water prior to use. The alkylating agents temozolomide (TMZ) and dacarbazine (DTIC) were purchased from Sigma-Aldrich.

\subsection{Cell viability}

MeWo cells were examined for viability by seeding cells $\left(10 \times 10^{3}\right)$ in quadruplicates in 96well plates. Cells were allowed to attach to the 96-well plate overnight in 5\% FBS containing medium prior to the indicated drug treatment and concentration for 36 hours. CellTiter ${ }^{\mathrm{TM}}$ Blue reagent (Promega, Madison, WI) was added to plates and cells were incubated at $37^{\circ} \mathrm{C}$ to assess viability as previously described (Altman et al. 2010; Hasegawa, Murph et al. 2008).

\subsection{High-throughput proliferation imaging}

To examine the effects of cell proliferation in the presence of monotherapy, $10 \times 10^{3} \mathrm{MeWo}$ cells were plated in quadruplicates in 96-well plates. After overnight incubation at $37^{\circ} \mathrm{C}$, the indicated drug and concentration was administered to the cells and the plates were incubated for another 30-40 h. After this incubation the cells were fixed in $2 \%$ formaldehyde 
and stained using the Multiparameter Cytotoxicity II kit (ThermoScientific, Pittsburgh, PA), according to the directions provided by the manufacturer. To obtain the results, the plates were then quantified and visualized using the ArrayScan ${ }^{\circledR V T I}$ HCS Reader (Thermo Scientific). For combination drug treatments, approximately 2,500 MeWo cells were plated in 96-wells and allowed to attach overnight. DTIC was added at the indicated concentration for $24 \mathrm{~h}$ followed by the addition of BrP-LPA for $24 \mathrm{~h}$. The cells were fixed and stained using the Multiparameter Cytotoxicity III kit and then following the directions given in the manufacturer's protocol (Thermo Scientific).

\subsection{Statistical analysis}

Statistical differences in experimental data was determined using analysis of variance (ANOVA) followed by either Tukey's test or Bonferroni's multiple comparison test between groups. Alternatively, single comparisons were calculated using the student's t-test. GraphPad Prism (La Jolla, CA) was used to facilitate the statistical tests performed. ${ }^{*} \mathrm{p}<0.05$ ${ }^{* *} p<0.01$ and ${ }^{* * *} p<0.001$ indicate the levels of significance.

\section{Results}

Figure 1 shows the chemical structures of the two BrP-LPA compounds used. Figure 1A shows the relative anti-configuration of the bromo substituent relative to the natural configuration of the sn-2 hydroxyl of LPA, while Figure 1B shows the diastereomeric mixture of syn- and anti-bromo substituents.

A<smiles>O=C(OC[C@@H](O)C[C@@H](Br)P(=O)(O)O)[Hg]c1ccccc1</smiles>

anti-BrP-LPA
B<smiles></smiles>

BrP-LPA

The structures of the anti diastereoisomer of 16:0 BrP-LPA (A) and its diastereomeric mixture (B) are depicted.

Fig. 1. Chemical structures.

We compared these two preparations in a viability curve, which accounts for both proliferation and metabolism, using MeWo melanoma cells. In the viability assay, we measured IC50 values of $17.68 \mu \mathrm{M}$ and $16.76 \mu \mathrm{M}$ for the anti diastereoisomer and the diastereomeric mixture, respectively (Figure 2A and 2B). Upon further analysis, the mixture (Figure 1B) consistently demonstrated increased ability to reduce cell viability over anti-BrPLPA (Figure 1A), especially at the highest concentration $(100 \mu \mathrm{M})$ tested (Figure 2C). 


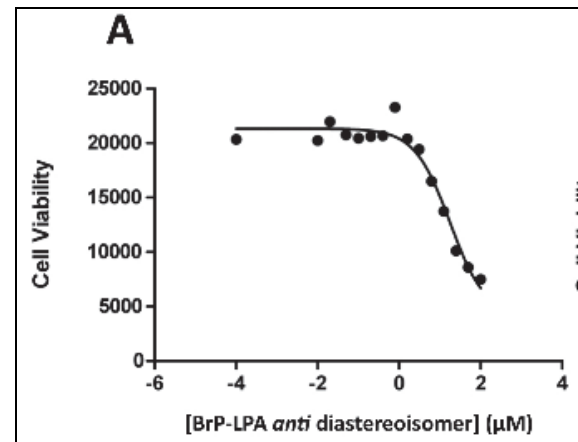

\section{B}
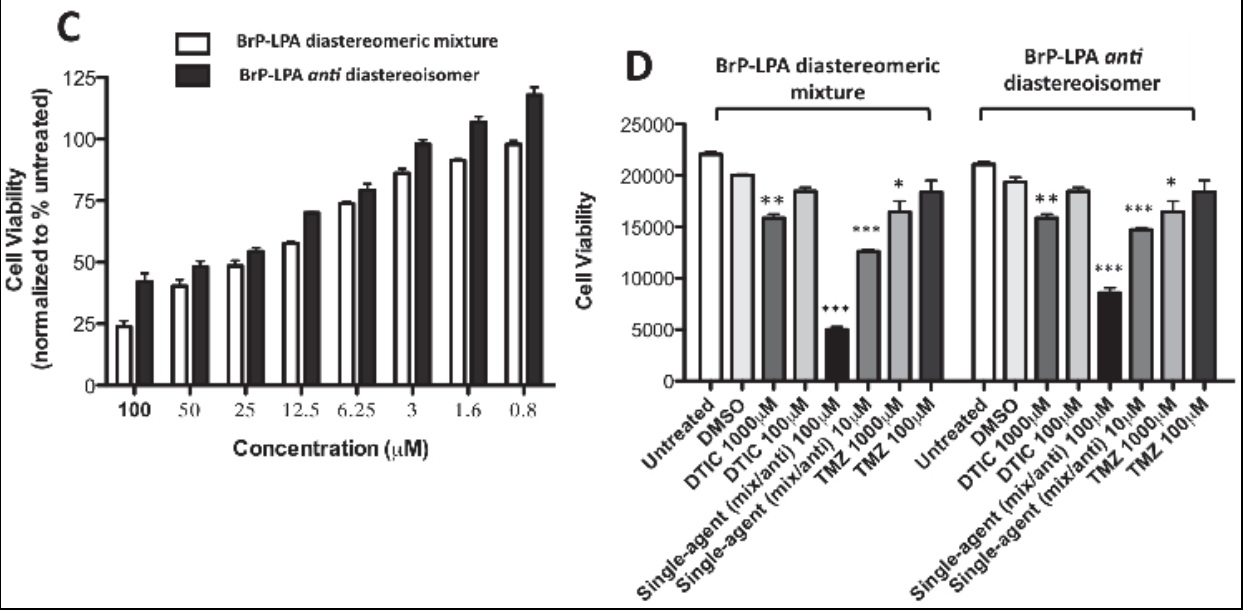

Cell viability assays using MeWo cells treated with increasing doses of the BrP-LPA anti diastereoisomer (A) or diastereomeric mixture (B) are log transformed and depicted here. (C) A bar graph showing the range of concentrations used in MeWo cells compares the reduction in viability achieved between the two BrP-LPA reagents. (D) Comparison between the two BrP-LPA reagents and other single-agent treatment with dacarbazine (DTIC) or temozolomide (TMZ) demonstrates potency of the BrP-LPA diastereomeric mixture $(100 \mu \mathrm{M}$ and $10 \mu \mathrm{M})$ surpasses that achieved by either DTIC or TMZ at higher doses $(1000 \mu \mathrm{M}$ and $100 \mu \mathrm{M})$. Similar results are also seen with the BrP-LPA anti diastereoisomer. Brackets at the top indicate which single-agent was used. ${ }^{*} \mathrm{p}<0.05,{ }^{* *} \mathrm{p}<0.01$ or ${ }^{* * *} \mathrm{p}<0.001$, compared to DMSO control-treated MeWo cells.

Fig. 2. Single-agent treatment with BrP-LPA compounds reduces cell viability at lower doses than dacarbazine or temozolomide.

We next sought to evaluate how these agents measured up against chemotherapy. In comparison to single-agent BrP-LPA treatment versus traditional alkylating chemotherapy, the BrP-LPA compounds showed more activity in reducing cell viability, even at lower concentrations than the chemotherapy (Figure 2D). For example, $100 \mu \mathrm{M}$ or $10 \mu \mathrm{M}$ of BrPLPA (Figure 1B) was more effective at reducing viability than $1000 \mu \mathrm{M}$ of dacarbazine (DTIC) or temozolomide (TMZ). At $100 \mu \mathrm{M}$ of DTIC or TMZ, the modest reduction in viability was not statistically different than diluent control (DMSO). Similar observations occurred with the anti-BrP-LPA (Figure 1A) as well. 


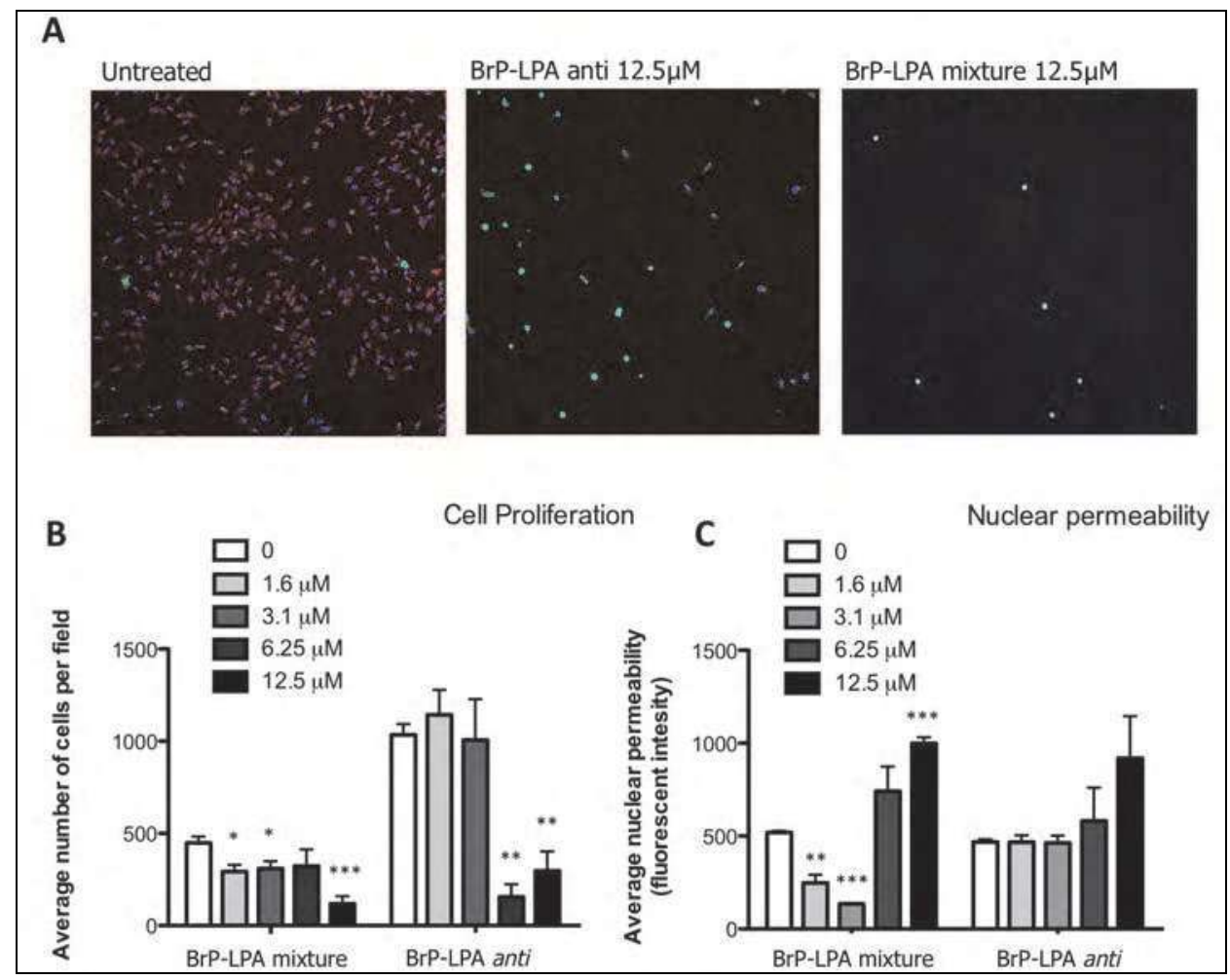

(A) MeWo cells were either untreated, or treated with $12.5 \mu \mathrm{M}$ BrP-LPA reagents for 36 hours, fixed, processed and stained for immunofluorescence visualization. (B) The average number of cells per field was calculated by automated measurements of quadruplicate well samples using the ArrayScan ${ }^{\circledR}$ VTI HCS Reader, as a measurement of the cell proliferation achieved in the presence of either $0,1.6,3.1,6.25$ or $12.5 \mu \mathrm{M}$ of the BrP-LPA diastereomeric mixture or the anti diastereoisomer. (C) Using a nuclear permeability dye, the increase in fluorescence intensity was automatically measured by the ArrayScan ${ }^{\circledR}$ VTI HCS Reader using quadruplicate samples. ${ }^{*} \mathrm{p}<0.05,{ }^{* *} \mathrm{p}<0.01$ or ${ }^{* * *} \mathrm{p}<0.001$, compared to $0 \mu \mathrm{M}$ or untreated MeWo cells.

Fig. 3. MeWo cell proliferation is reduced after treatment with BrP-LPA reagents.

Since the assay measuring cell viability accounts for both the proliferation and metabolism of cells, we sought to discriminate these two features by looking solely at the rate of in vitro growth or proliferation in the presence of BrP-LPA. After treating MeWo cells for 36 hours in the presence of increasing concentration of drug (Figure 3A), we assessed the number of surviving cells using high-throughput imaging for quantification. Strikingly, even the lowest concentration of the mixture BrP-LPA (Figure 1B) $(1.6 \mu \mathrm{M})$ showed a significant decrease in the number of cells captured per field compared with untreated cells (Figure 3B). At the highest dose $(12.5 \mu \mathrm{M})$, an obvious shift in cell number was visually observed (Figure 3A) and was also quantified as statistically significant versus untreated cells (Figure 3B). Although a reduction in cell number was detected among cells treated with the anti-BrPLPA (1A), the reductions were significant only at $6.25 \mu \mathrm{M}$ and $12.5 \mu \mathrm{M}$. Dying cells display many morphological changes, including nuclear condensation and permeabilization that 
can be visualized by an intense increase in the fluorescence intensity of cell nuclei. We quantified nuclear permeability and detected an initial reduction $(1.6 \mu \mathrm{M}$ and $3.1 \mu \mathrm{M})$, followed by a significant increase at higher concentrations $(6.25 \mu \mathrm{M}$ and $12.5 \mu \mathrm{M})$ in MeWo cells treated with the BrP-LPA mixture (Figure 1B) (Figure 3C). Although the results from the anti-BrP-LPA (Figure 1A) were not significant, there did appear to be an increasing trend at higher concentrations $(6.25 \mu \mathrm{M}$ and $12.5 \mu \mathrm{M})$.

Due to the favorable results we observed thus far in our analysis, we hypothesized that the combinatorial treatment of BrP-LPA compounds with the alkylating agent DTIC would have superior activity to reduce MeWo cell viability than single-agent BrP-LPA treatment. In contrast, we observed an increase in the number of remaining MeWo cells after 24 hours treatment with DTIC, followed by 24 hours of the BrP-LPA compounds (Figure 4A). We quantified the changes in the loss of cells and determined monotherapy of BrP-LPA to be superior in comparison with combinatorial treatment (Figure 3B and 3C).

Only when DTIC was reduced to $50 \mu \mathrm{M}$ did the significance return, suggesting that a low enough concentration eliminated the combined inhibition. Similarly, we detected plasma membrane permeability only among DTIC $1000 \mu \mathrm{M}$ and single-agent anti or mix $(10 \mu \mathrm{M})$. There was a slight increase in the permeability at $50 \mu \mathrm{M}$ DTIC and $10 \mu \mathrm{M}$ of anti or mix, further supporting the observation that the low dose of DTIC eliminates the combined inhibition. Since the drugs were administered 24 hours apart, we hypothesize this is due to the molecular and cellular response to the compound, within the context of proliferation or an effect related to chemoresistance. This could suggest that the BrP-LPA compounds would require chemonaïve patients to achieve therapeutic efficacy, and this group would be incredibly difficult to find.

\section{Discussion}

Our data suggests, at least in an in vitro comparison, that single-agent or monotherapy using the anti-BrP-LPA (Figure 1A) or the mixed diastereomers BrP-LPA (Figure 1B) is superior at reducing the viability and proliferation of MeWo primary cutaneous melanoma cells than dacarbazine or temozolomide. Although we hypothesized that the mechanism of action for these two different agents would create a synergistic response as others have seen using combinations of dacarbazine with unrelated agents (Jin, Gong et al. 2011), in fact that is not what was observed. While unexpected, our results are similar to what others have also observed using BrP-LPA. Using an in vivo breast cancer model, Zhang et al. reported that the mixed diastereomers BrP-LPA (Figure 1B) alone $(10 \mathrm{mg} / \mathrm{kg}$ ) was superior at reducing tumor burden, compared with taxol alone $(10 \mathrm{mg} / \mathrm{kg}$ ) or taxol followed by BrP-LPA (Zhang et al. 2009). This corroborates our observations and further predicts that similar effects are likely to occur in an in vivo model of melanoma. Indeed, we have tested single-agent BrPLPA against metastatic melanoma in vivo and measured a significant reduction in the number of lesions in the lungs of animals (data not shown).

The concern over reduced response with combination treatment of a novel agent together with dacarbazine is a major concern since most chemotherapy is now given in combination, even in clinical trials (Chu and DeVita 2008). In our study, we staged the drugs 24 hours apart, yet we still observed a reduction in overall efficacy. Our results are also in agreement with other publications suggesting that dacarbazine selects for a more aggressive phenotype 

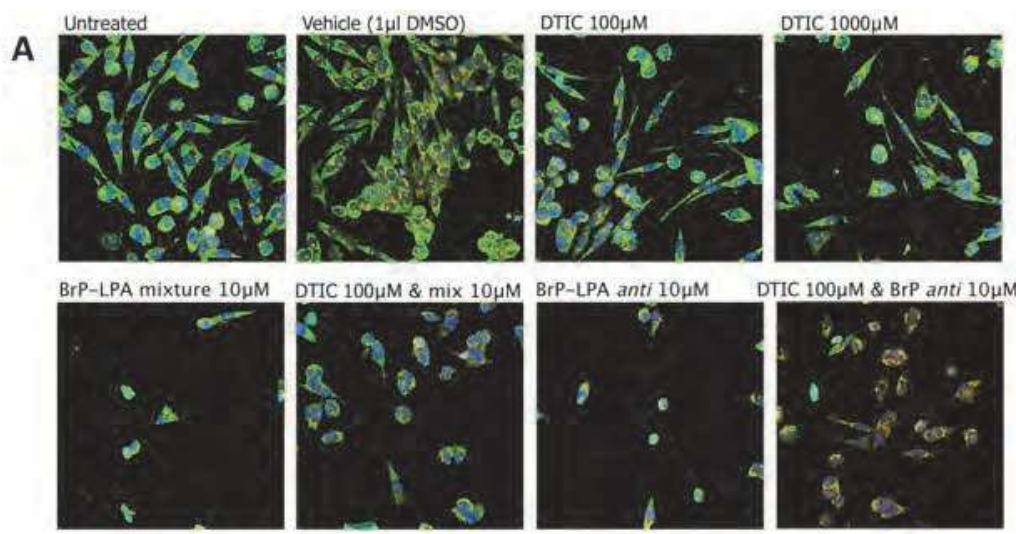

Cell Loss

B

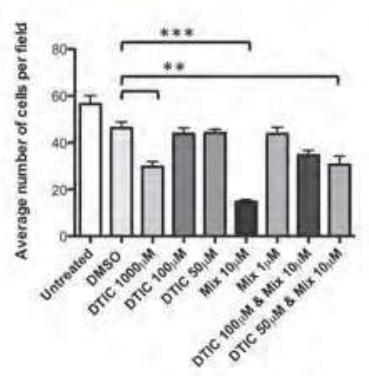

C
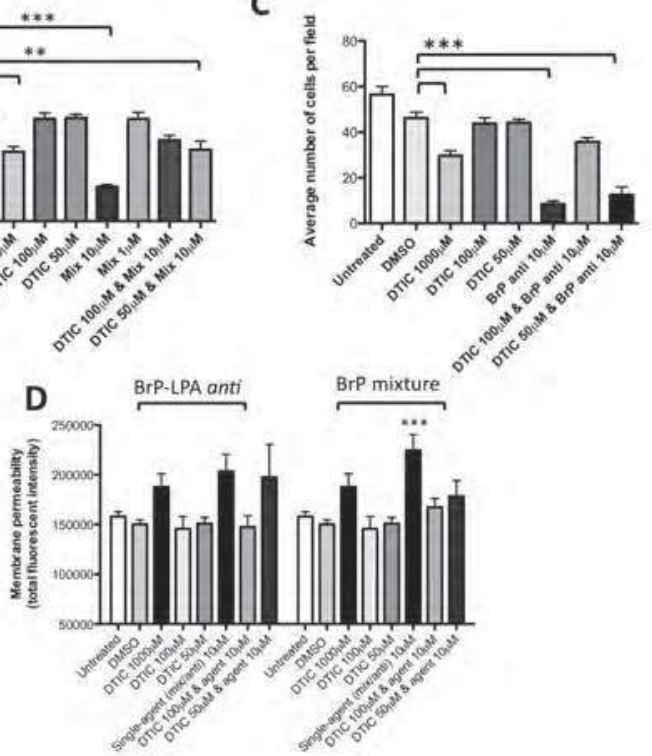

(A) Fluorescent images of MeWo cells treated with the indicated reagents for 24 or $48 \mathrm{~h}$. The combination treatments were staged so that the dacarbazine (DTIC) was added for $24 \mathrm{~h}$ prior to the addition of BrP-LPA for an additional $24 \mathrm{~h}$, for a total of $48 \mathrm{~h}$ of dacarbazine. The single-agent treatments were for $24 \mathrm{~h}$. (B and C) Cell loss was calculated by measuring the average number of cells lost per field from quadruplicate samples and at least 4 images taken per sample for $\mathrm{N}=16$. The $\mathrm{BrP}$ LPA diastereomeric mixture was used in ' $\mathrm{B}$ ' and the anti diastereoisomer was used in ' $\mathrm{C}$ '. (D) Plasma membrane permeability was calculated after staining the MeWo cells with a fluorescent dye capable of penetrating the membrane when small pores or holes provide access for the dye to enter the cell. An increase in the membrane permeability was achieved in the single-agent conditions or when DTIC was very low $(50 \mu \mathrm{M})$, although statistical significance $\left.{ }^{* * *} \mathrm{p}<0.001\right)$ was calculated for only the BrP-LPA diastereomeric mixture $(10 \mu \mathrm{M})$ in comparison with DMSO $(1 \mu \mathrm{M})$ control using the student's t-test.

Fig. 4. Combination treatment of BrP-LPA reagents with dacarbazine inhibits the reduction in cell loss and proliferation achieved using single-agents. 
of melanoma, which may occur through the upregulation of ERK signaling pathways, cytokine release or increased vascular endothelial growth factor (Lev, Onn et al. 2004). In this study we also observed what others have reported in that melanomas are notoriously resistant to therapeutic intervention. Indeed, we also found this to be true after only 24 hours of exposure to dacarbazine, which was unexpected given the short timecourse.

Herein we showed a reduction in cell viability using BrP-LPA compounds over the traditional chemotherapy alkylating agents, even when using BrP-LPA at lower concentrations. This highlights two important points concerning current therapeutics of melanoma. First, the traditional alkylating agents lack sufficient potency against this type of tumor, even when drug delivery is removed from the equation through the use of an in vitro tissue culture model. Second, single-agent BrP-LPA could be far better in generating a reduction in tumor burden and clinical usage than the alkylating agents.

In comparison with other agents that we have tested, the BrP-LPA compounds can generate a more robust effect against certain types of melanoma than thio-ccPA 18:1, which requires a higher dosage in vitro (Altman et al. 2010). Furthermore, in a direct comparison between anti-BrP-LPA (Figure 1A) and the mixed diastereomers BrP-LPA (Figure 1B), we repeatedly observed an enhanced effect of the mixture. Thus far, in vivo studies have not detected any known cytotoxicity of this compound (data not shown), which further indicates its utility. Taken together, this is suggestive of the clinical potential of BrP-LPA in advanced melanoma.

\section{Acknowledgments}

This work was supported by a grant from the Georgia Cancer Coalition (to M.M.M).

Glenn Prestwich is a scientific advisor for Echelon Biosciences, Inc. and RxBio.

\section{References}

Albers HM, Dong A, van Meeteren LA, Egan DA, Sunkara M, van Tilburg EW, Schuurman K, van Tellingen O, Morris AJ, Smyth SS, Moolenaar WH, Ovaa H (2010) Boronic acid-based inhibitor of autotaxin reveals rapid turnover of LPA in the circulation. Proc Natl Acad Sci U S A 107: 7257-7262

Altman MK, Gopal V, Jia W, Yu S, Hall H, Mills GB, McGinnis AC, Bartlett MG, Jiang G, Madan D, Prestwich GD, Xu Y, Davies MA, Murph MM (2010) Targeting melanoma growth and viability reveals dualistic functionality of the phosphonothionate analogue of carba cyclic phosphatidic acid. Mol Cancer 9: 140

Aoki J, Bandoh K, Inoue K (2000) A novel human G-protein-coupled receptor, EDG7, for lysophosphatidic acid with unsaturated fatty-acid moiety. Ann N Y Acad Sci 905: 263-266

Baker DL, Fujiwara Y, Pigg KR, Tsukahara R, Kobayashi S, Murofushi H, Uchiyama A, Murakami-Murofushi K, Koh E, Bandle RW, Byun HS, Bittman R, Fan D, Murph M, Mills GB, Tigyi G (2006) Carba analogs of cyclic phosphatidic acid are selective inhibitors of autotaxin and cancer cell invasion and metastasis. J Biol Chem 281: 22786-22793

Bandoh K, Aoki J, Hosono H, Kobayashi S, Kobayashi T, Murakami-Murofushi K, Tsujimoto M, Arai H, Inoue K (1999) Molecular cloning and characterization of a novel human 
G-protein-coupled receptor, EDG7, for lysophosphatidic acid. J Biol Chem 274: 27776-27785

Block RC, Duff R, Lawrence P, Kakinami L, Brenna JT, Shearer GC, Meednu N, Mousa S, Friedman A, Harris WS, Larson M, Georas S (2010) The effects of EPA, DHA, and aspirin ingestion on plasma lysophospholipids and autotaxin. Prostaglandins Leukot Essent Fatty Acids 82: 87-95

Chu E, DeVita VT (2008) Physicians' Cancer Chemotherapy Drug Manual. Jones and Bartlett Publishers, Sudbury, MA

Flaherty KT, Puzanov I, Kim KB, Ribas A, McArthur GA, Sosman JA, O'Dwyer PJ, Lee RJ, Grippo JF, Nolop K, Chapman PB (2010) Inhibition of mutated, activated BRAF in metastatic melanoma. N Engl J Med 363: 809-819

Hasegawa Y, Murph M, Yu S, Tigyi G, Mills GB (2008) Lysophosphatidic acid (LPA)induced vasodilator-stimulated phosphoprotein mediates lamellipodia formation to initiate motility in PC-3 prostate cancer cells. Mol Oncol 2: 54-69

Hodi FS, O'Day SJ, McDermott DF, Weber RW, Sosman JA, Haanen JB, Gonzalez R, Robert C, Schadendorf D, Hassel JC, Akerley W, van den Eertwegh AJ, Lutzky J, Lorigan P, Vaubel JM, Linette GP, Hogg D, Ottensmeier CH, Lebbe C, Peschel C, Quirt I, Clark JI, Wolchok JD, Weber JS, Tian J, Yellin MJ, Nichol GM, Hoos A, Urba WJ (2010) Improved survival with ipilimumab in patients with metastatic melanoma. N Engl J Med 363: 711-723

Hoeglund AB, Bostic HE, Howard AL, Wanjala IW, Best MD, Baker DL, Parrill AL (2010) Optimization of a pipemidic acid autotaxin inhibitor. J Med Chem 53: 1056-1066

Hoeglund AB, Howard AL, Wanjala IW, Pham TC, Parrill AL, Baker DL (2010) Characterization of non-lipid autotaxin inhibitors. Bioorg Med Chem 18: 769-776

Jemal A, Siegel R, Xu J, Ward E (2010) Cancer statistics, 2010. CA Cancer J Clin 60: 277-300

Jin JL, Gong J, Yin TJ, Lu YJ, Xia JJ, Xie YY, Di Y, He L, Guo JL, Sun J, Noteborn MH, Qu S (2011) PTD4-apoptin protein and dacarbazine show a synergistic antitumor effect on B16-F1 melanoma in vitro and in vivo. Eur J Pharmacol 654: 17-25

Kim C, Lee CW, Kovacic L, Shah A, Klasa R, Savage KJ (2010) Long-term survival in patients with metastatic melanoma treated with DTIC or temozolomide. Oncologist 15: 765771

Lev DC, Onn A, Melinkova VO, Miller C, Stone V, Ruiz M, McGary EC, Ananthaswamy HN, Price JE, Bar-Eli M (2004) Exposure of melanoma cells to dacarbazine results in enhanced tumor growth and metastasis in vivo. J Clin Oncol 22: 2092-2100

Liu S, Murph M, Panupinthu N, Mills GB (2009) ATX-LPA receptor axis in inflammation and cancer. Cell Cycle 8: 3695-3701

North EJ, Howard AL, Wanjala IW, Pham TC, Baker DL, Parrill AL (2010) Pharmacophore development and application toward the identification of novel, small-molecule autotaxin inhibitors. J Med Chem 53: 3095-3105

Stracke ML, Krutzsch HC, Unsworth EJ, Arestad A, Cioce V, Schiffmann E, Liotta LA (1992) Identification, purification, and partial sequence analysis of autotaxin, a novel motility-stimulating protein. J Biol Chem 267: 2524-2529

Thompson, JF, Morton, DL, Kroon, BRB (2004) Textbook of Melanoma. Martin Dunitz, Taylor \& Francis Group, ISBN:1901865657, London, United Kingdom 
Xu X, Prestwich GD (2010) Inhibition of tumor growth and angiogenesis by a lysophosphatidic acid antagonist in an engineered three-dimensional lung cancer xenograft model. Cancer 116: 1739-1750

Xu X, Yang G, Zhang H, Prestwich GD (2009) Evaluating dual activity LPA receptor panantagonist/autotaxin inhibitors as anti-cancer agents in vivo using engineered human tumors. Prostaglandins Other Lipid Mediat 89: 140-146

Zhang H, Xu X, Gajewiak J, Tsukahara R, Fujiwara Y, Liu J, Fells JI, Perygin D, Parrill AL, Tigyi G, Prestwich GD (2009) Dual activity lysophosphatidic acid receptor panantagonist/autotaxin inhibitor reduces breast cancer cell migration in vitro and causes tumor regression in vivo. Cancer Res 69: 5441-5449 


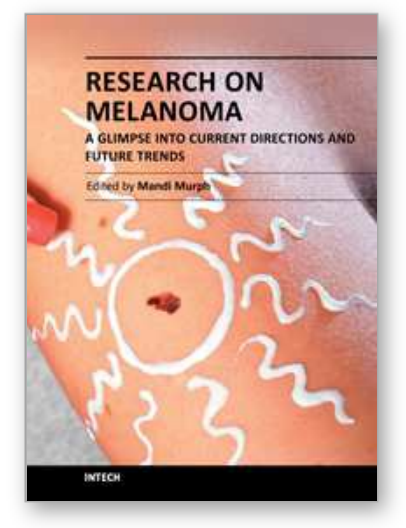

\author{
Research on Melanoma - A Glimpse into Current Directions and \\ Future Trends \\ Edited by Prof. Mandi Murph
}

ISBN 978-953-307-293-7

Hard cover, 414 pages

Publisher InTech

Published online 12, September, 2011

Published in print edition September, 2011

The book Research on Melanoma: A Glimpse into Current Directions and Future Trends, is divided into sections to represent the most cutting-edge topics in melanoma from around the world. The emerging epigenetics of disease, novel therapeutics under development and the molecular signaling aberrations are explained in detail. Since there are a number of areas in which unknowns exist surrounding the complex development of melanoma and its response to therapy, this book illuminates and comprehensively discusses such aspects. It is relevant for teaching the novice researcher who wants to initiate projects in melanoma and the more senior researcher seeking to polish their existing knowledge in this area. Many chapters include visuals and illustrations designed to easily guide the reader through the ideas presented.

\title{
How to reference
}

In order to correctly reference this scholarly work, feel free to copy and paste the following:

Duy Nguyen, Oanh Nguyen, Honglu Zhang, Glenn D. Prestwich and Mandi M. Murph (2011). A Bromophosphonate Analogue of Lysophosphatidic Acid Surpasses Dacarbazine in Reducing Cell Proliferation and Viability of MeWo Melanoma Cells, Research on Melanoma - A Glimpse into Current Directions and Future Trends, Prof. Mandi Murph (Ed.), ISBN: 978-953-307-293-7, InTech, Available from: http://www.intechopen.com/books/research-on-melanoma-a-glimpse-into-current-directions-and-futuretrends/a-bromophosphonate-analogue-of-lysophosphatidic-acid-surpasses-dacarbazine-in-reducing-cellprolifer

\section{INTECH}

open science | open minds

\section{InTech Europe}

University Campus STeP Ri

Slavka Krautzeka 83/A

51000 Rijeka, Croatia

Phone: +385 (51) 770447

Fax: +385 (51) 686166

www.intechopen.com

\section{InTech China}

Unit 405, Office Block, Hotel Equatorial Shanghai

No.65, Yan An Road (West), Shanghai, 200040, China

中国上海市延安西路65号上海国际贵都大饭店办公楼 405 单元

Phone: $+86-21-62489820$

Fax: $+86-21-62489821$ 
(C) 2011 The Author(s). Licensee IntechOpen. This chapter is distributed under the terms of the Creative Commons Attribution-NonCommercialShareAlike-3.0 License, which permits use, distribution and reproduction for non-commercial purposes, provided the original is properly cited and derivative works building on this content are distributed under the same license. 